\title{
Dynamic Analysis of a Real Footbridge Structure in a Najaf City
}

\author{
Saad Al Wazni ${ }^{1 *}$, Alaa Abdalabbas², Roqia Hayder² and Zainab Mierr ${ }^{2}$ \\ ${ }^{1}$ Department of Civil Engineering, University of Kufa, Iraq \\ ${ }^{2}$ Student at department of Civil Eng, University of Kufa, Iraq
}

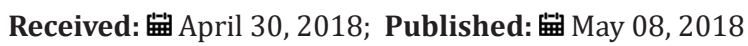

*Corresponding author: Saad Al Wazni, Department of Civil Engineering, Faculty of Engineering, University of Kufa, Iraq, Email: Saad.alwazni@uokufa.edu.iq

\begin{abstract}
The presented study consists of a dynamic analysis of a real pedestrian bridge structure of about 35m span over the highway connect Kufa and centre city of Najaf (Iraq). The main objective of this analysis were to assess whether the dynamic properties of footbridge structure meets the main safety requirements with the appropriate verification criteria. The extracted dynamic properties of the structural bridge model are natural frequency and mode shape. ANSYS software is used to perform the analysis by the way of APDL method. In this study, the first seven vibration modes of the bridge model are extracted. The dynamic characteristics extracted by modal analysis of the adopted bridge structural model exhibited the uncomfortable of vibration modes compared with European standards.
\end{abstract}

Keywords: Dynamic properties; Modal analysis; Footbridge; Pedestrian bridge; Steel structure

\section{Introduction}

For any structure has own natural dynamic behaviour depend on its stiffness and mass. The dynamic behaviour of a structure is represented by dynamic properties such as natural frequency and mode shape. The modal analysis method is applied to extract the dynamic properties of the structure [1]. If the structure excited by the external force has frequency close to the it's natural frequency, the resonance will occur and that means the structure will face higher vibrations [2]. The changes of the modal properties are related with geometry, material properties and mass of the structure. In the design of the structure, the extracted modal properties using dynamic analysis helps to specify the weakness that needs modifications. So, calculating the natural frequency and mode shape of a vibrating structure are a common types of dynamic analysis and they are called "eignvalue and eigenvector analyses" respectively.

\section{Structural Dynamic System}

The natural frequency, $\omega$, is in units of radians per second $(\mathrm{rad} / \mathrm{s})$. The typical units displayed on a digital signal analyser, however, are in Hertz (Hz). To analyse equation the system shown in the Figure 1, the force acting on the system is summed up. This becomes [3];

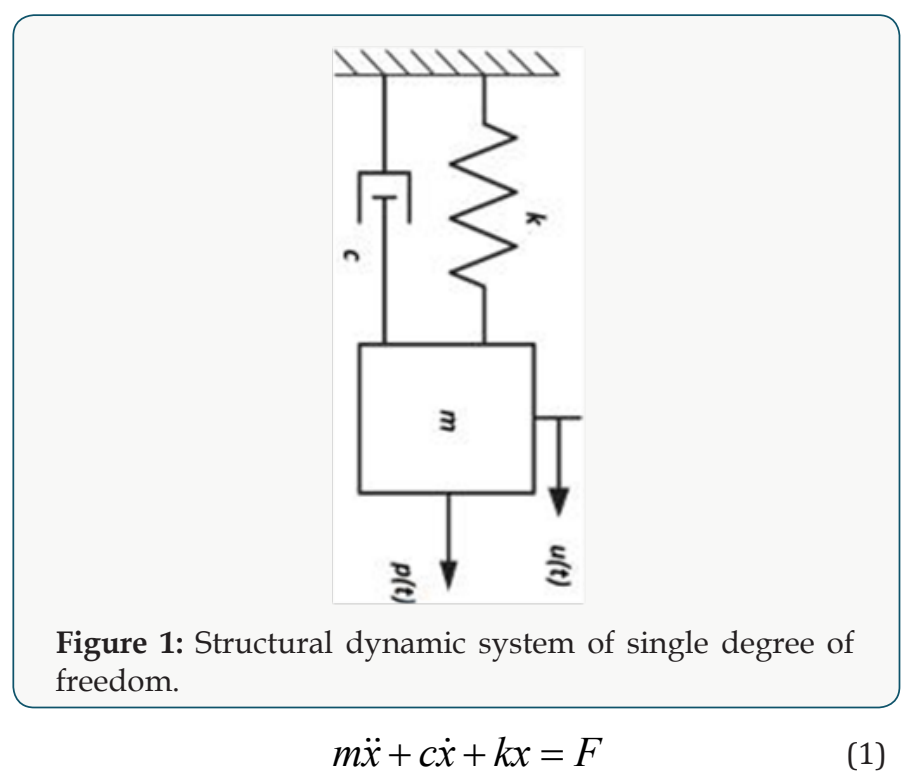

where $\ddot{x}$ is acceleration, $\dot{x}$ is velocity, $x$ is displacement, $c$ is damping constant, $k$ is stiffness and $\mathrm{F}$ is excitation force. If the displacement and the force are written as a cosine function, such that: 


$$
x=X \cdot \cos \omega t
$$

and

$$
F=F_{O .} \cos \omega_{n} t
$$

the equation becomes:

$$
-m \cdot \omega^{2} \cdot X \cdot \cos \omega t+c \cdot \omega \cdot X \cdot \sin \omega t+k \cdot X \cdot \cos \omega t=F_{0} \cdot \cos \omega_{n} t
$$

For undamped vibrations, $c=0$, the equation becomes;

$$
\begin{gathered}
-m \cdot \omega^{2} \cdot X \cdot \cos \omega t+k \cdot X \cdot \cos \omega t=F_{0} \cdot \cos \omega_{n} t \\
-m \cdot \omega^{2} \cdot X+k \cdot X=F_{0}
\end{gathered}
$$

and for free vibrations, $F_{O}=0$, the equation becomes:

$$
\begin{gathered}
-m \cdot \omega^{2} \cdot X+k \cdot X=0 \\
m \cdot \omega^{2}=k
\end{gathered}
$$

Thus:

$$
\omega^{2}=k / m
$$

where $\omega$ is the circular frequency of the structure.

\section{Adopted Pedestrian Bridge Structure}

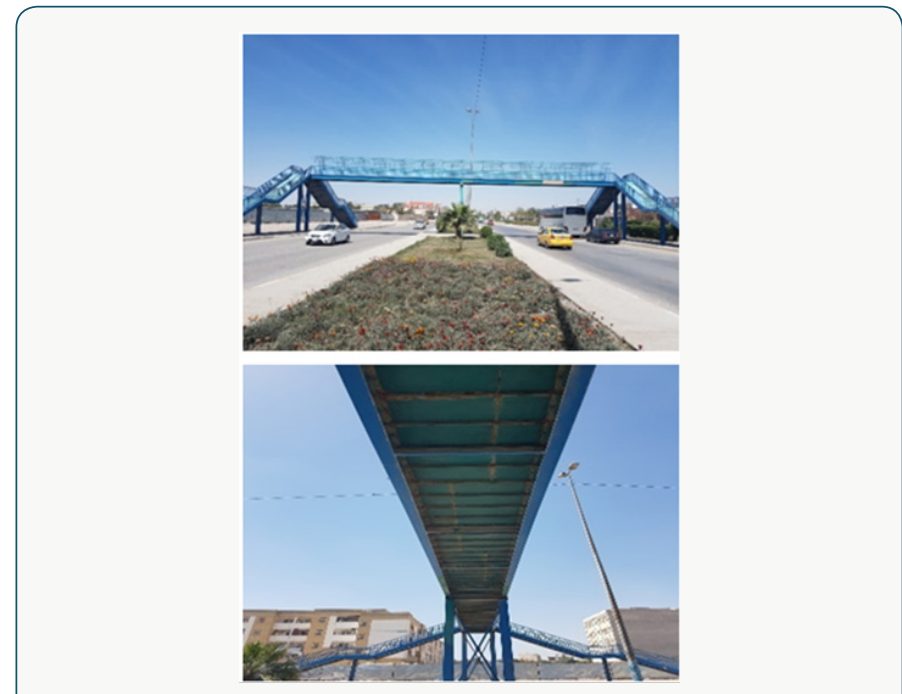

Figure 2: The adopted real pedestrian bridge structure.

The studied bridge structure in this paper is a pedestrian bridge, is located in the city of Najaf in Iraq. The city of Najaf is one of the most prominent cities in Iraq and located to the south west of the capital Baghdad far about $170 \mathrm{~km}$. The adopted structure is a pedestrian steel bridge erected on the main highway leading to the centre of the Najaf near Alghadir neighbour. The highway under the pedestrian bridge is a three-lane one-way with two directions for vehicular traffic, as shown in the Figure 2. The geometry of the real bridge structure is flexural grid floor model with a length of $34.9 \mathrm{~m}$ and $2.1 \mathrm{~m}$ span width supported on the three piers at height of $5.5 \mathrm{~m}$, as shown the Figure 3. The grid floor of the bridge model consists of two main girders of H-section with dimension of ( $400 \times 300 \times 13)$ $\mathrm{mm}$ connected by transverse channel cross section beams of (200 x 50 x 5)mm distributed uniformly along the length of structure. In addition, the stiffeners beams of angle cross section with dimension $(75 \times 75 \times 5) \mathrm{mm}$ connected at the top of both main girders to carry floor plate of $3 \mathrm{~mm}$ section, as shown the Figure 3. The three piers of the structure are distributed at distance of $16.15 \mathrm{~m} \mathrm{c} / \mathrm{c}$ in the longitudinal direction of the structure. Each Pier has dual column with transverse distance of $1.5 \mathrm{~m} \mathrm{c} / \mathrm{c}$, and connected each to other by angle cross section stiffeners beams, as shown the Figure 3. All the parts of the bridge structural model are welded together. The values of material properties are assumed as follows: modulus of elasticity of $\mathrm{E}=200 \mathrm{GPa}$, Poisson's ratio $\mathrm{n}=0.3$ and mass density $\mathrm{r}=7.850 \times 10^{3} \mathrm{~kg} / \mathrm{m}^{3}$. The fences of the bridge structure are neglected and the stairs are represented as additional constrained in the supporting of the structural bridge model.

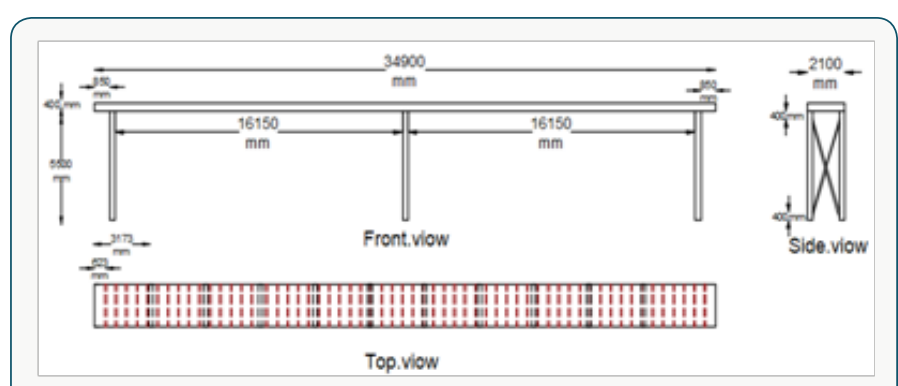

Figure 3: The geometry of real pedestrian bridge structure.

\section{Finite Element Modelling}

The FE model of the steel grid bridge structural model consists of 167 nodes and 249 elements with different element lengths. The hidden elements are considered for piers supporting in lateral direction. Those elements are adopted to suppress local behaviour of transverse stiffeners beams of piers. Thus, zero mass density is assumed for those elements with the same angle cross section dimensions of $(50 \times 50 \times 5) \mathrm{mm}$. The selection of different element lengths is adopted in order to reduce the number of elements of FE model. The finite element analysis (FEA) is carried out using ANSYS-v18 software for structural analysis by Ansys Parametric Design Language (APDL) method. The APDL method is easiest way to simulate the structural model in ANSYS software. However, it is complex for who did not use it, so needs more experience to simulate the real structural model. The important of the APDL is easy, flexible and more effective if there are a lot of changed parameters and connect the ANSYS software with software such as MATLAB software [4]. The Beam4 element type and linear elastic isotropic homogenous material are applied in the modal analysis. The first five modes of structural model for the assumed values of material properties used in FE model are selected in the analysis. The supporting of the columns of the bridge structure is fixed in the bottom with ground base. Instead of the stairs, the restricted supporting nodes are created in the upper side and release rotations in some axes to simulate the behaviour of stairs joints with the bridge structure. There is no loading applied into the bridge structure to extract modal properties, only the mass and stiffness of structural bridge model are used. 

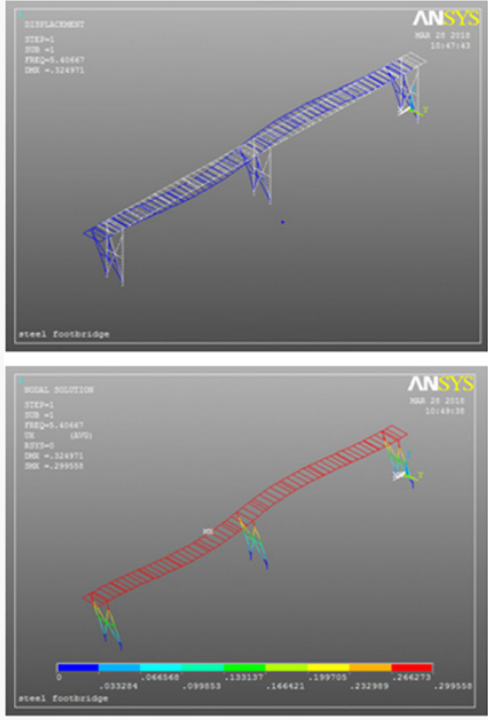

(a) $1^{\text {st }}$ Mode shape, $\mathrm{f}=5.407 \mathrm{~Hz}$.
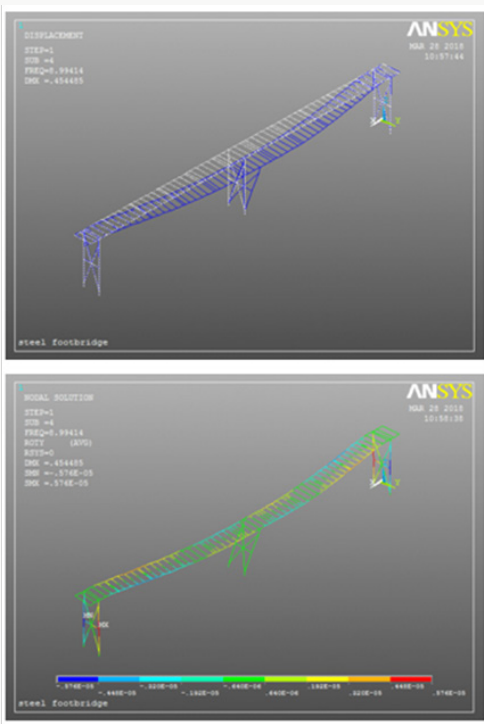

(d) $4^{\text {th }}$ Mode shape, $\mathrm{f}=8.9941 \mathrm{~Hz}$.
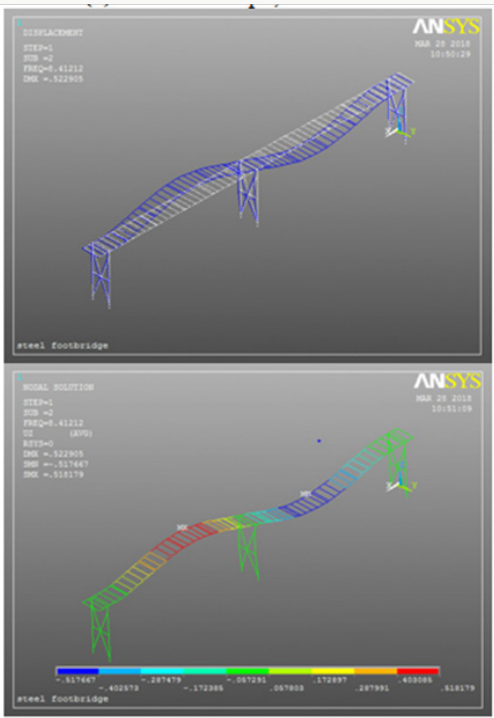

(b) $2^{\text {nd }}$ Mode shape, $f=8.4121 \mathrm{~Hz}$.
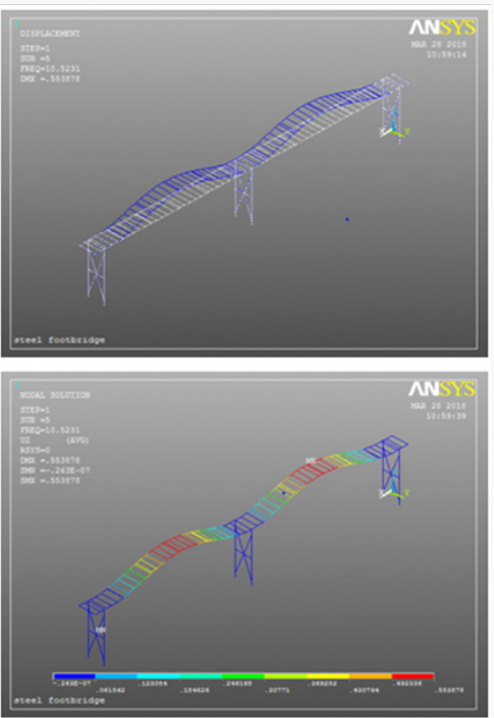

(e) $5^{\text {th }}$ Mode shape, $f=10.5230 \mathrm{~Hz}$.
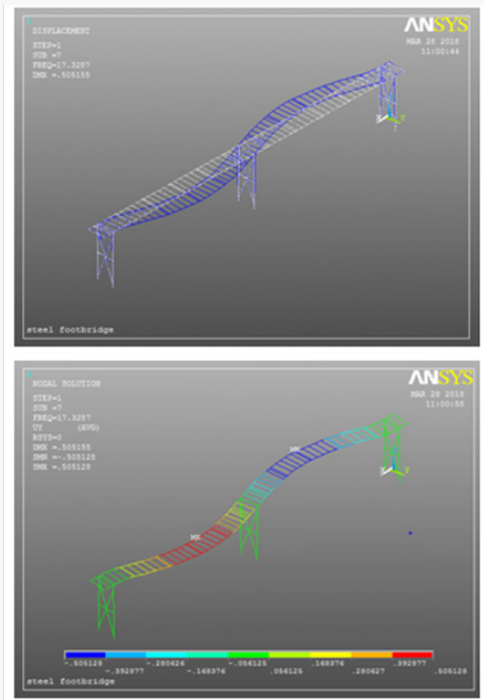

(g) $7^{\text {th }}$ Mode shape, $\mathrm{f}=17.3280 \mathrm{~Hz}$.
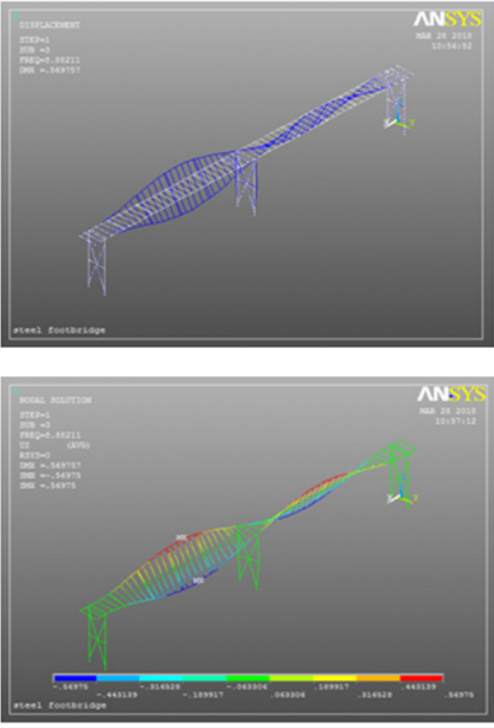

(C) $3^{\text {rd }}$ Mode shape, $\mathrm{f}=8.8821 \mathrm{~Hz}$.
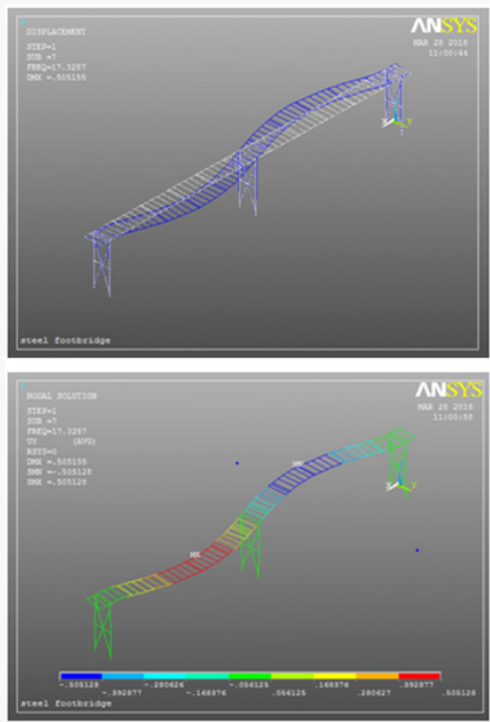

(f) $6^{\text {th }}$ Mode shape, $f=11.2860 \mathrm{~Hz}$.

Figure 4: The mode shapes of pedestrian bridge structure. 


\section{Results}

The results obtained from the modal analysis are the natural frequencies and the mode shapes of the adopted bridge structure. The natural frequencies values for first seven modes are listed in Table 1. The Type of mode shapes of the first seven corresponding natural frequencies is listed in Table 2 shown in Figure 2. The mode shapes, the maximum and minimum relative displacements in each direction of the first seven corresponding natural frequencies are shown in Figure 4a-g and it shows the first seven mode shapes of the adopted pedestrian bridge structure.

Table 1: The Natural Frequencies Values of Pedestrian Bridge Structure.

\begin{tabular}{|c|c|}
\hline Mode No. & Frequency Value (Hz) \\
\hline 1 & 5.4067 \\
\hline 2 & 8.4121 \\
\hline 3 & 8.8821 \\
\hline 4 & 8.9941 \\
\hline 5 & 10.5230 \\
\hline 6 & 11.2860 \\
\hline 7 & 17.3280 \\
\hline
\end{tabular}

Table 2: Type of mode shape of pedestrian bridge structure.

\begin{tabular}{|c|c|}
\hline Mode No. & Type of Mode \\
\hline 1 & Longitudinal \\
\hline 2 & $1^{\text {st }}$ Bending unsymmetrical \\
\hline 3 & $1^{\text {st }}$ Torsion unsymmetrical \\
\hline 4 & $1^{\text {st }}$ lateral symmetrical \\
\hline 5 & $1^{\text {st }}$ Torsion symmetrical \\
\hline 6 & $1^{\text {st }}$ Bending symmetrical \\
\hline 7 & $1^{\text {st }}$ lateral unsymmetrical \\
\hline
\end{tabular}

\section{Code Standard}

The Verification of the comfort criteria, according to Euro codes [5-7], should be performed if the structure has lateral or torsional modes of vibration lower than $2.5 \mathrm{~Hz}$ and verti $\neg$ cal modes of vibration lower than $5 \mathrm{~Hz}$. The comfort criteria serves as recommended maximum levels of acceleration and it is up to the designer to determine whether it is necessary to make provisions in the design for damping after the structure is built [5-7].

\section{Conclusion}

The modal analysis of the pedestrian bridge using ANSYS APDL software was sufficient to identify seven modes below $20 \mathrm{~Hz}$. The first mode being fully coupled longitudinal with the first bending vibration frequency. The fundamental vertical frequency was identified as $8.4121 \mathrm{~Hz}$. The fundamental torsional mode was also observed uncoupled at $8.8821 \mathrm{~Hz}$. The fundamental transverse frequency was identified as $8.9941 \mathrm{~Hz}$. The fundamental horizontal frequency was $17.3280 \mathrm{~Hz}$. The results show consistent of the bending, torsional and transverse modes. In modes 4,5 and 6 the symmetrical exist. The results of the dynamic analysis showed that all frequency values exceed the standards according to euro code. The results of the dynamic analysis showed that all frequency values exceed the standards according to euro code. The range of vertical frequencies is between $8.4121 \mathrm{~Hz}-11.2860 \mathrm{~Hz}$, the range of lateral frequency is between $8.9941 \mathrm{~Hz}-17.3280 \mathrm{~Hz}$ and the range of torsion frequencies is between $8.8821 \mathrm{~Hz}-10.5230 \mathrm{~Hz}$. Where vertical and torsional frequencies values are exceed $682.4 \%$ for the lowest vertical frequency, while the ratio exceeded the greater vertical frequency is $1257.2 \%$. As well as the override ratios for the lateral frequency is $2597.64 \%-5931.2 \%$, while the torsional frequencies are in between 255.28\%- 3209.2\%. Therefore, the vibration of the studied bridge in this project is not in conformity with standards, as it exceeds the permitted values.

\section{References}

1. B Ivan, A Marco, L Mathias (2014) Physically and Geometrically Nonlinear Vibrations of Thin Rectangular Plates. International Journal of Non Linear Mechanics 58: 30-40.

2. G Polytech (2001) Basic of Experimental Modal Analysis. Polytec GmbH, Polytec Platz, Waldbronn Germany.

3. A Chopra (2014) Dynamics of Structures-Theory and Applications to Earthquake. ( $4^{\text {th }}$ edn), Prentice Hall, USA.

4. ANSYS Inc, v-18, help guide.

5. (2006) Footbridges: assessment of vibrational behavior of footbridges under pedestrian loading. Roads and Bridges Engineering and Road Safety, Paris, France.

6. (2005) Eurocode 0: Basic of structural design. Appendix 2: Application for bridges, European Standard Norme.

7. British Standards Institution (2003) UK National Annex to Eurocode 1: Action on structures-Part 2: Traffic loads on bridges, NA, London.

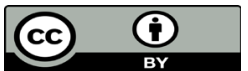

This work is licensed under Creative Commons Attribution 4.0 License

To Submit Your Article Click Here:

Submit Article

DOI: $10.32474 /$ TCEIA.2018.02.000133

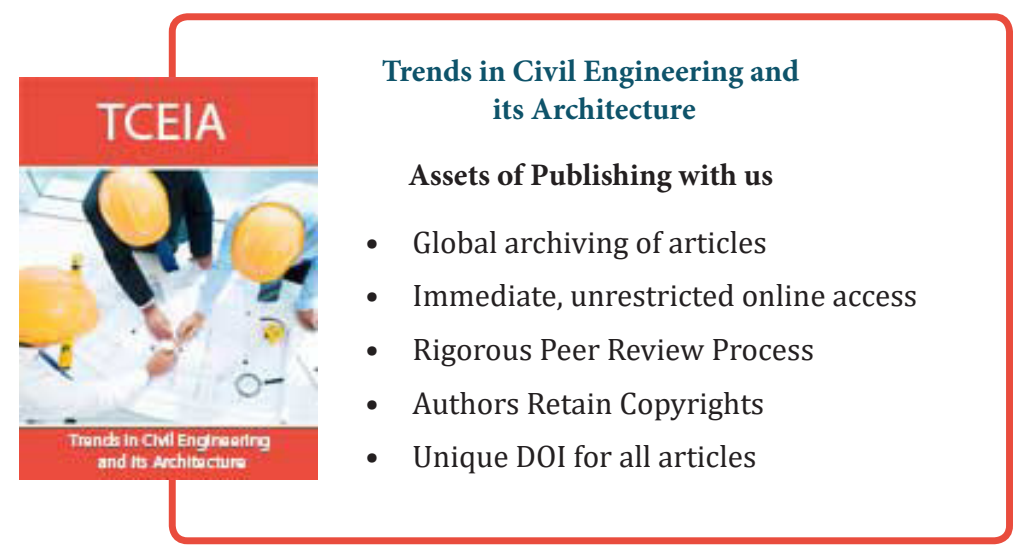

Citation: Saad Al W, Alaa A, Roqia H, Zainab M. Dynamic Analysis of a Real Footbridge Structure in a Najaf City. Tr Civil Eng \& Arch 2(2)- 2018. 